\title{
Changes in cysteinyl leukotrienes during and after cardiac surgery with cardiopulmonary bypass in patients with and without chronic obstructive pulmonary disease
}

\author{
Nicolas de Prost, MD, PhD, Claudine El-Karak, MD, Maria Avila, MD, Fumito Ichinose, MD, PhD, and \\ Marcos F. Vidal Melo, MD, PhD
}

\begin{abstract}
Objective: Pulmonary function frequently deteriorates after cardiopulmonary bypass (CPB). Chronic obstructive pulmonary disease (COPD) increases risk of respiratory complications after CPB. Cysteinyl leukotrienes are important mediators of respiratory dysfunction. Their role during cardiac surgery and its lung complications is incompletely understood. We studied whether production of cysteinyl leukotrienes changes during and after cardiac surgery with CPB and differs between patients with and without COPD.
\end{abstract}

\begin{abstract}
Methods: Patients with $(\mathrm{n}=9)$ and without $(\mathrm{n}=10)$ moderate-to-severe COPD undergoing cardiac surgery with CPB were prospectively included. Plasma and urinary cysteinyl leukotriene and leukotriene $\mathrm{B}_{4}$ concentrations were measured by enzyme-linked immunosorbent assay after anesthesia induction, at end of CPB, after CPB, and 2 hours after intensive care unit admission. Gas exchange and respiratory mechanics were also assessed.
\end{abstract}

\begin{abstract}
Results: Patients with COPD had larger airway resistances after CPB and chest closure $(P<.001)$, lower ratio of arterial $\mathrm{Po}_{2}$ to inspired oxygen fraction at intensive care unit admission $(215 \pm 37 \mathrm{vs} 328 \pm 30 \mathrm{~mm} \mathrm{Hg}, P<.05)$, and longer postoperative mechanical ventilation $(13.7 \pm 5.8$ vs $6.8 \pm 3.4$ hours, $P<.01)$. Urinary cysteinyl leukotriene concentrations increased with time in both groups $(P<.01)$, but more in patients with than without COPD $(P<.05)$. Plasma cysteinyl leukotriene concentrations increased significantly between baseline and intensive care unit admission in patients with but not without $\operatorname{COPD}(P<.01)$. Concentrations of leukotriene $\mathrm{B}_{4}$ in plasma and urine did not increase significantly with time and were not different between groups.
\end{abstract}

Conclusions: Release of cysteinyl leukotrienes increases during cardiac surgery with CPB and is larger in patients with than without COPD. This may be related to higher lung and airway production of cysteinyl leukotrienes and neutrophil activation in patients with COPD. (J Thorac Cardiovasc Surg 2011;141:1496-502)

Supplemental material is available online.

Chronic obstructive pulmonary disease (COPD) ranks number 4 among the causes of death in the United States. ${ }^{1}$ COPD because atherosclerotic cardiovascular disease is closely linked to smoking and affects $4 \%$ to $27 \%$ of patients undergoing coronary artery bypass grafting $(\mathrm{CABG}){ }^{2}$ Moreover, after cardiac surgery COPD is an in-

From the Department of Anesthesia, Critical Care, and Pain Medicine, Massachusetts General Hospital and Harvard Medical School, Boston, Mass.

Supported by an investigator-initiated grant from Merck \& Co. Nicolas de Prost was supported by a scholarship from La Société de Pneumologie de Langue Française, and Fumito Ichinose was supported by the National Institutes of Health R01HL101930.

Disclosures: Authors have nothing to disclose with regard to commercial support. Received for publication June 3, 2010; revisions received Oct 13, 2010; accepted for publication Jan 20, 2011; available ahead of print March 7, 2011.

Address for reprints: Marcos F. Vidal Melo, MD, PhD, Department of Anesthesia, Critical Care and Pain Medicine, Massachusetts General Hospital, 55 Fruit St, Boston, MA 02114 (E-mail: mvidalmelo@partners.org).

$0022-5223 / \$ 36.00$

Copyright (C) 2011 by The American Association for Thoracic Surgery doi: $10.1016 /$ j.jtcvs.2011.01.035 dependent predictor of in-hospital mortality ${ }^{3}$ and a risk factor for extubation failure and prolonged mechanical ventilation, ${ }^{4}$ likely compounding with the respiratory dysfunction that follows cardiac surgery. ${ }^{5}$

Leukotrienes are 5-lipoxygenase metabolites of arachidonic acid predominantly synthesized by leukocytes. Cysteinyl leukotrienes (leukotrienes $\mathrm{C}_{4}, \mathrm{D}_{4}$, and $\mathrm{E}_{4}$ ) mediate bronchoconstriction, vasoconstriction, and increase vascular permeability. ${ }^{6,7}$ Cysteinyl leukotriene inhibition is used clinically mainly in the modulation of bronchoconstriction in aspirin- and exercise-induced asthma. ${ }^{8}$ Patients with moderate-to-severe COPD may benefit from cysteinyl leukotriene inhibition, as shown by the attenuation of their hypertonic saline solution-induced bronchoconstriction. ${ }^{9}$ Cysteinyl leukotrienes appear to be important in experimen$\mathrm{tal}^{10}$ and clinical acute lung injury. ${ }^{11}$ Previous studies suggested increases in blood ${ }^{12}$ and urinary ${ }^{13}$ cysteinyl leukotrienes during and after cardiac surgery with cardiopulmonary bypass (CPB). Those studies, however, did not address the association between COPD and blood or urinary cysteinyl leukotriene levels, used high-dose aprotinin, ${ }^{12}$ and were performed more than 10 years ago, when surgical techniques and CPB system biocompatibility may well have led to higher inflammatory responses than those 


\section{Abbreviations and Acronyms \\ $\mathrm{CABG}=$ coronary artery bypass grafting \\ $\mathrm{COPD}=$ chronic obstructive pulmonary disease \\ $\mathrm{ICU}=$ intensive care unit \\ $\mathrm{LTB}_{4}=$ leukotriene B4}

observed currently. As a consequence, despite the known respiratory dysfunction after $\mathrm{CPB}^{14}$ and the significant percentage of patients with COPD undergoing cardiac surgery, there is no information on the intraoperative and immediate postoperative changes in cysteinyl leukotrienes during cardiac surgery in patients with and without COPD.

Leukotriene $\mathrm{B}_{4}\left(\mathrm{LTB}_{4}\right)$, another 5-lipoxygenase product, is a powerful endogenously synthesized chemotactic factor for granulocytes that is involved in the accumulation of neutrophils in the airways in COPD. ${ }^{15}$ In cardiac surgery, increases of $\mathrm{LTB}_{4}$ have been observed in bronchoalveolar lavage fluid ${ }^{16}$ and blood during and after CPB. ${ }^{12,17,18}$ $\mathrm{LTB}_{4}$ has also been suggested as a key mediator of postoperative acute respiratory failure.

We hypothesized that the systemic inflammatory response to cardiac surgery with $\mathrm{CPB}$ exacerbates the chronic inflammation present in patients with COPD, leading to higher production of cysteinyl leukotrienes in patients with COPD than in those without COPD. To test this hypothesis, we measured both plasma and urinary levels of cysteinyl leukotrienes in patients with and without COPD undergoing cardiac surgery with $\mathrm{CPB}$. We evaluated whether (1) the production of cysteinyl leukotrienes is increased during cardiac surgery, (2) the changes in cysteinyl leukotriene levels differ according to the presence of COPD, and (3) changes in plasma and urinary levels of $\mathrm{LTB}_{4}$ and in lung function variables parallel changes in cysteinyl leukotriene levels.

\section{MATERIALS AND METHODS \\ Study Subjects}

This prospective, single-center study was approved by the institutional review board of the Massachusetts General Hospital (approval number 2007P000164), and written, informed consent was obtained from all subjects. Twenty patients undergoing cardiac surgery with CPB between August 2007 and August 2008 were studied: 10 patients with moderate or severe COPD, as defined by Global Initiative for Chronic Obstructive Lung Disease criteria, ${ }^{19}$ and 10 patients without COPD and with no history of either smoking or pulmonary disease (control group). Exclusion criteria were the presence of acute respiratory failure, previous diagnosis of asthma, and emergency surgery. Patient disease severity at intensive care unit (ICU) admission was assessed with the Simplified Acute Physiologic Score 3 score. $^{20}$ Aspirin treatment during the 7 days preceding surgery was recorded to account for its role as a confounding factor given its effects on the modulation of the 5-lipoxygenase pathway through inhibition of cyclooxygenase. ${ }^{21}$

\section{Procedures}

Regular medication was maintained until surgery. Patients were medicated in advance with midazolam hydrochloride (INN midazolam); under- went anesthesia induction with fentanyl and propofol; had anesthesia maintenance with isoflurane, midazolam, and fentanyl; and had muscle paralysis induced with cisatracurium besylate (INN cisatracurium besilate) or pancuronium bromide. Standard monitoring, including electrocardiography, pulse oximetry, radial artery catheterization, and pulmonary artery catheterization was performed. Patients were mechanically ventilated with a tidal volume of $8 \mathrm{~mL} / \mathrm{kg}$, an inspired oxygen fraction of 1 , and a positive end-expiratory pressure of $2.5 \mathrm{~cm} \mathrm{H}_{2} \mathrm{O}$, with respiratory rate adjusted to maintain normocarbia. Ventilator parameters were kept constant before and after CPB.

All procedures were performed through a median sternotomy. CPB was performed with activated clotting time greater than 480 seconds, systemic cooling to $30^{\circ} \mathrm{C}$ to $33^{\circ} \mathrm{C}$, and ascending aortic cannulation. Venous cannulation was performed with a single double-stage right atrial cannula in all cases except that of patient 7, in whom direct cannulation of both the superior and inferior venae cavae was used. Cardiac arrest was achieved by cold or warm blood antegrade and retrograde cardioplegia. The flow was maintained at $2.4 \mathrm{~L} /\left(\mathrm{min} \cdot \mathrm{m}^{2}\right)$, with a mean arterial pressure greater than $50 \mathrm{~mm}$ $\mathrm{Hg}$. During CPB, the expiratory limb of the breathing circuit was opened to the atmosphere with lungs passively deflated. Before weaning from $\mathrm{CPB}$, at least 1 recruitment maneuver to a peak inspiratory pressure of 20 to $25 \mathrm{~cm}$ $\mathrm{H}_{2} \mathrm{O}$ with direct visualization of lung expansion was performed.

\section{Cardiopulmonary Function Measurements}

Hemodynamic measurements were systemic and pulmonary arterial pressures, central venous pressure, and cardiac output. Respiratory measurements included arterial blood gas values and respiratory system compliance and airway resistance obtained with a respiratory analyzer (NICO; Respironics, Philips Healthcare, Best, The Netherlands). All function measurements were performed at 5 time points: (1) after intubation but before sternotomy (baseline), (2) after sternotomy but before CPB, (3) after CPB but before chest closure, (4) after chest closure at the end of surgery, and (5) 2 hours after arrival in the ICU.

\section{Leukotriene Measurements}

Blood and urine samples were drawn at 4 time points chosen to represent major phases: (1) after intubation but before sternotomy (baseline), (2) at the end of CPB while still on extracorporeal circulation, (3) after CPB but before chest closure, and (4) 2 hours after arrival in the ICU. Urinary leukotrienes could not be measured in 1 patient with COPD (patient 13; Table E1) who had previously known chronic renal failure and became anuric during surgery. Tracheal aspirates were sampled at baseline and after $\mathrm{CPB}$ only when required as part of the patient's care.

Cysteinyl leukotrienes and $\mathrm{LTB}_{4}$ concentrations were measured with an enzyme-linked immunosorbent assay (Neogen Corporation, Lexington, Ky). Plasma samples were lipid extracted with the $\mathrm{C}_{18}$ Sep-Pak light column (Waters Corporation, Milford, Mass) before leukotriene measurement. Urinary leukotriene concentrations were normalized to urinary creatinine to account for urine dilution changes. ${ }^{13}$ Plasma leukotriene concentrations were corrected for changes in plasma protein concentration at each time point relative to baseline to take into account plasma dilution during surgery.

\section{Statistical Analysis}

All results are expressed as mean $\pm \mathrm{SD}$ or median with interquartile range (25th-75th percentile). Because of the paucity of human data, we based the power analysis for cysteinyl leukotriene measurements on animal experiments. ${ }^{10}$ Considering a significance level of .05 , a power of .8 , and a 2-sided hypothesis, we estimated that 8 patients in each study group would be necessary. Statistical analysis was performed with SAS statistical software (version 9; SAS Institute Inc, Cary, NC). Categoric variables were compared with the $\chi^{2}$ test or the Fisher Exact test as required. Continuous data that were normally distributed were compared with the $t$ test or otherwise with the Mann-Whitney test. Two-way analysis of variance with 
repeated measures was used to compare groups (COPD vs no COPD) at different time points. Bonferroni corrected post hoc tests were performed when overall $P$ value was less than .05 .

\section{RESULTS \\ Patients Characteristics at Baseline and During and After Surgery}

Nineteen patients $($ COPD $n=9$, no COPD $n=10)$ were included in the final analysis (Table E1). One patient with COPD was excluded because of the intraoperative decision to perform off-pump CABG. Patient demographic characteristics and surgical procedures were distributed similarly between groups (Table 1).

White blood cell counts increased dramatically between baseline and ICU admission for both groups of patients (Figure E1, A), with no significant difference between groups. In the COPD group, there was a significant increase in white blood cell counts from chest closure to 2 hours after ICU admission. Platelet counts decreased significantly from baseline to chest closure and from baseline to 2 hours after ICU admission for both groups of patients (Figure E1, $B$ ), with no difference between groups.

At ICU admission, both groups of patients had similar Simplified Acute Physiologic Score 3 values, hemodynamic values, and blood hemoglobin and urea nitrogen concentrations (Table 1). Patients with COPD exhibited a lower arterial $\mathrm{pH}(P<.03)$ and a higher arterial $\mathrm{PCO}_{2}(P<.03)$ than did patients without COPD.

Patients with COPD had a longer duration of mechanical ventilation than did patients without COPD $(13.7 \pm 5.8$ vs $6.8 \pm 3.4$ hours, $P<.01$; Table E2). At ICU admission, plasma cysteinyl leukotriene levels of patients who required mechanical ventilation for longer than 10 hours tended to be higher than those of patients who did not $(4.0 \pm 1.0 \mathrm{vs} 2.3 \pm$

TABLE 1. Patient characteristics at intensive care unit admission

\begin{tabular}{|c|c|c|c|}
\hline & $\begin{array}{l}\text { COPD } \\
(n=9) \\
\end{array}$ & $\begin{array}{c}\text { No COPD } \\
(\mathbf{n}=\mathbf{1 0})\end{array}$ & $\begin{array}{c}P \\
\text { value } \\
\end{array}$ \\
\hline Age $(y$, mean $\pm S D)$ & $69 \pm 9$ & $64 \pm 11$ & .24 \\
\hline No. male & 7 & 6 & .72 \\
\hline CABG (No.) & 7 & 6 & .72 \\
\hline Bypass time (min, mean $\pm \mathrm{SD})$ & $123 \pm 41$ & $118 \pm 56$ & .81 \\
\hline $\begin{array}{l}\text { Aortic crossclamp time } \\
\qquad(\min , \text { mean } \pm \mathrm{SD})\end{array}$ & $86 \pm 27$ & $85 \pm 37$ & .94 \\
\hline $\begin{array}{l}\text { Simplified Acute Physiologic } \\
\text { Score } 3^{20}(\text { mean } \pm \text { SD })\end{array}$ & $51 \pm 10$ & $47 \pm 7$ & .24 \\
\hline Cardiac output $(\mathrm{L} / \mathrm{min}$, mean $\pm \mathrm{SD})$ & $4.0 \pm 1.3$ & $4.2 \pm 1.0$ & .59 \\
\hline Heart rate (beats/min, mean $\pm \mathrm{SD}$ ) & $87 \pm 5$ & $86 \pm 5$ & .58 \\
\hline Arterial $\mathrm{pH}($ mean $\pm \mathrm{SD})$ & $7.39 \pm 0.5$ & $7.45 \pm 0.5$ & .03 \\
\hline Arterial $\mathrm{PCO}_{2}(\mathrm{~mm} \mathrm{Hg}$, mean $\pm \mathrm{SD})$ & $40 \pm 7$ & $33 \pm 4$ & .03 \\
\hline Hemoglobin $(\mathrm{g} / \mathrm{dL}$, mean $\pm \mathrm{SD})$ & $10.2 \pm 0.9$ & $10.4 \pm 1.3$ & .74 \\
\hline $\begin{array}{l}\text { Blood urea nitrogen }(\mathrm{mg} / \mathrm{dL}, \\
\text { median and interquartile range })^{*}\end{array}$ & $20(12-26)$ & $12(10-16)$ & .14 \\
\hline
\end{tabular}

$1.9 \mathrm{ng} / \mathrm{mL}, P=.051)$. There was a higher, although not statistically significant, proportion of postoperative atrial fibrillation in patients with COPD than without (Table 2). One patient in the COPD group (patient 18; Table E1) died on postoperative day 17 .

\section{Gas Exchange and Respiratory Mechanics}

The ratio of arterial $\mathrm{PO}_{2}$ to inspired oxygen fraction did not differ at baseline between patients with and without COPD. The ratio decreased significantly during surgery $(P<.001)$, with no difference between groups (Figure 1, $A)$. Patients with COPD, however, had significantly lower ratios of arterial $\mathrm{PO}_{2}$ to inspired oxygen fraction than did patients without COPD 2 hours after ICU admission ( $215 \pm 37$ vs $328 \pm 30 \mathrm{~mm} \mathrm{Hg}, P<.05$ ).

Trends in airway resistance were significantly different in the 2 groups (Figure 1, B). At baseline, mean airway resistance was numerically but not statistically higher in patients with COPD than in patients without COPD. Resistance increased significantly with time $(P<.001)$ and was higher in patients with COPD than in patients without COPD both after CPB $\left(9.7 \pm 2.7\right.$ vs $\left.7.8 \pm 2.0 \mathrm{~cm} \mathrm{H}_{2} \mathrm{O} /[\mathrm{L} \cdot \mathrm{s}], P<.001\right)$ and after chest closure $\left(13.2 \pm 2.9\right.$ vs $7.4 \pm 1.4 \mathrm{~cm} \mathrm{H}_{2} \mathrm{O} /[\mathrm{L}$. $\mathrm{s}], P<.001)$.

Compliance of the respiratory system did not significantly differ between patients with COPD and patients without COPD (Figure E2). Compliance increased significantly in patients without COPD, however, before and after CPB relative to baseline and after chest closure $(P<.01)$.

\section{Leukotriene Measurements}

Cysteinyl leukotrienes. Plasma cysteinyl leukotriene concentrations (Figure 2, A) changed significantly with time $(P<.001)$. Starting from similar baseline values for both groups (COPD $1.5 \pm 0.3$ vs no COPD $=2.0 \pm 0.3 \mathrm{ng} / \mathrm{mL}$, $P=.31$, cysteinyl leukotrienes increased significantly between baseline and end of CPB in patients without COPD $(P<.05)$ and tended to increase significantly in patients with COPD $(P=.08)$. Plasma cysteinyl leukotrienes in patients with COPD were significantly higher 2 hours after arrival in the ICU than at baseline $(P<.01)$ and after CPB $(P<0.1)$. Mean plasma cysteinyl leukotriene concentrations were similar in patients who received aspirin $(\mathrm{n}=13,2.4 \pm$ $1.1 \mathrm{ng} / \mathrm{mL})$ and in those who did not $(\mathrm{n}=6,2.2 \pm 0.7 \mathrm{ng} / \mathrm{mL}$, $P=.60)$.

Urinary cysteinyl leukotriene concentrations presented a clearly different pattern in patients with and without COPD (Figure 2, $B)$. Values increased with time $(P<.001)$ and were higher in patients with COPD than in patients without COPD ( $P<.05$ for effect of group). Starting from similar values at baseline for both groups (COPD $0.5 \pm 0.1$ vs no COPD $0.5 \pm 0.1 \mathrm{ng} / \mathrm{mg}$ creatinine, $P=.66$ ), post hoc tests showed that cysteinyl leukotriene urinary concentrations tended to be higher in patients with COPD than in patients 


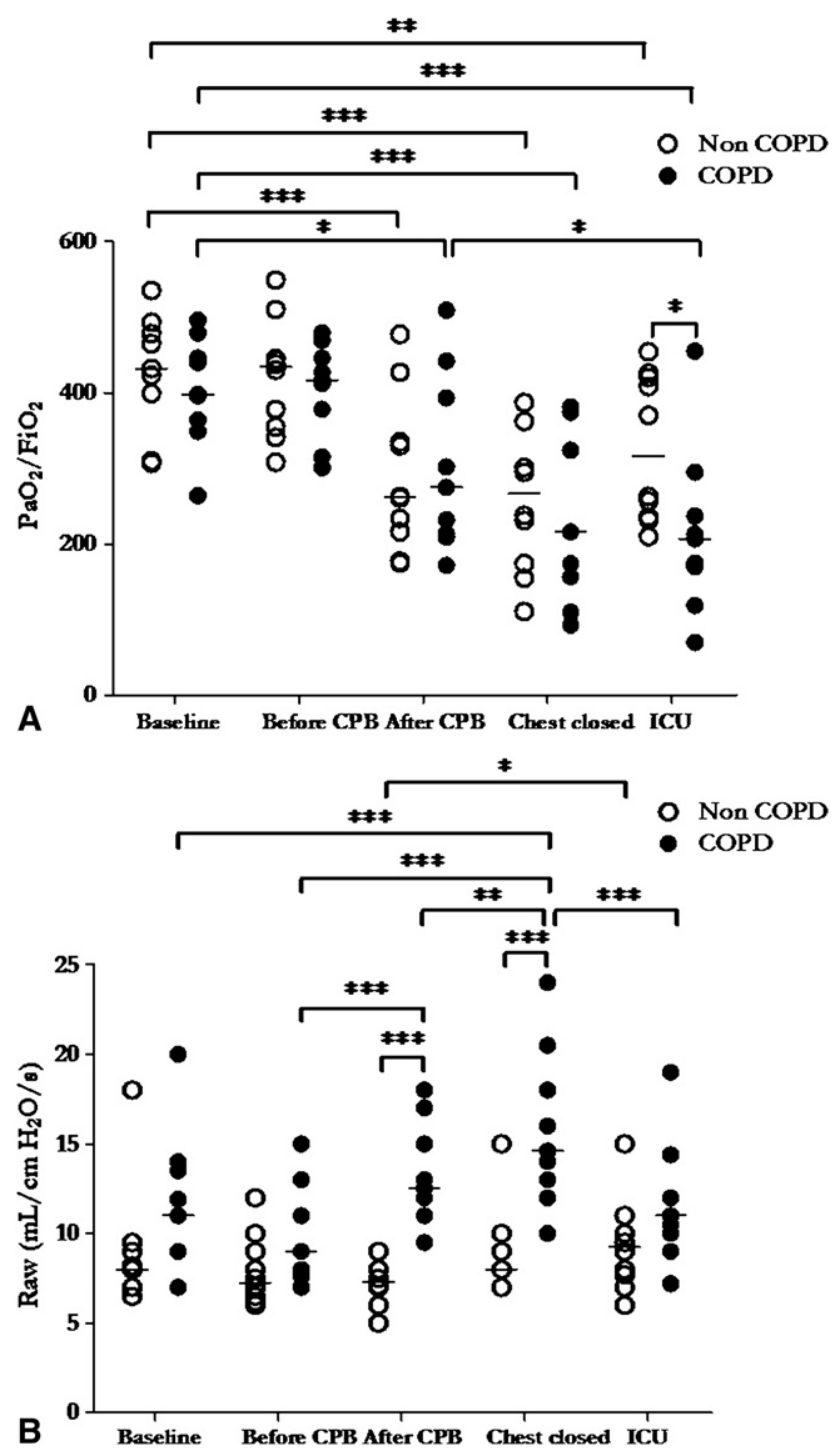

FIGURE 1. Ratio of arterial $\mathrm{PO}_{2}\left(\mathrm{PaO}_{2}\right)$ to inspired oxygen fraction $\left(\mathrm{Fio}_{2}\right.$; A) and airway resistances $(\mathrm{Raw} ; \mathrm{B})$ of patients with chronic obstructive pulmonary disease $(C O P D$, filled circles, $\mathrm{n}=9$ ) and without chronic obstructive pulmonary disease (non-COPD, open circles, $\mathrm{n}=10$ ) at $5 \mathrm{ma}-$ jor interventional phases: before sternotomy (Baseline), before and after cardiopulmonary bypass $(C P B)$, after chest closure (chest closed), and 2 hours after intensive care unit admission $(I C U)$. Horizontal bars represent median values. Single asterisk indicates $P<.05$; double asterisk indicates $P<.01$; triple asterisk indicates $P<.001 . P$ values are derived from 2 -way analysis of variance with repeated measurements, with Bonferroni adjustments for multiple comparisons.

without COPD both at the end of $\mathrm{CPB}(3.0 \pm 0.7 \mathrm{vs} 1.5 \pm 0.3$ $\mathrm{ng} / \mathrm{mg}$ creatinine, $P=.08)$ and after CPB (3.4 \pm 0.8 vs $2.0 \pm$ $0.4 \mathrm{ng} / \mathrm{mg}$ creatinine, $P=.06$ ).

Leukotriene $\mathbf{B}_{4}$. Plasma $\mathrm{LTB}_{4}$ concentrations tended to increase with time $(P=.06)$ after similar group values at baseline (COPD $2.1 \pm 0.5$ vs no COPD $2.2 \pm 0.7 \mathrm{ng} / \mathrm{mL}$, $P=.93$ ), with no effect of group (Figure E3, A). Mean

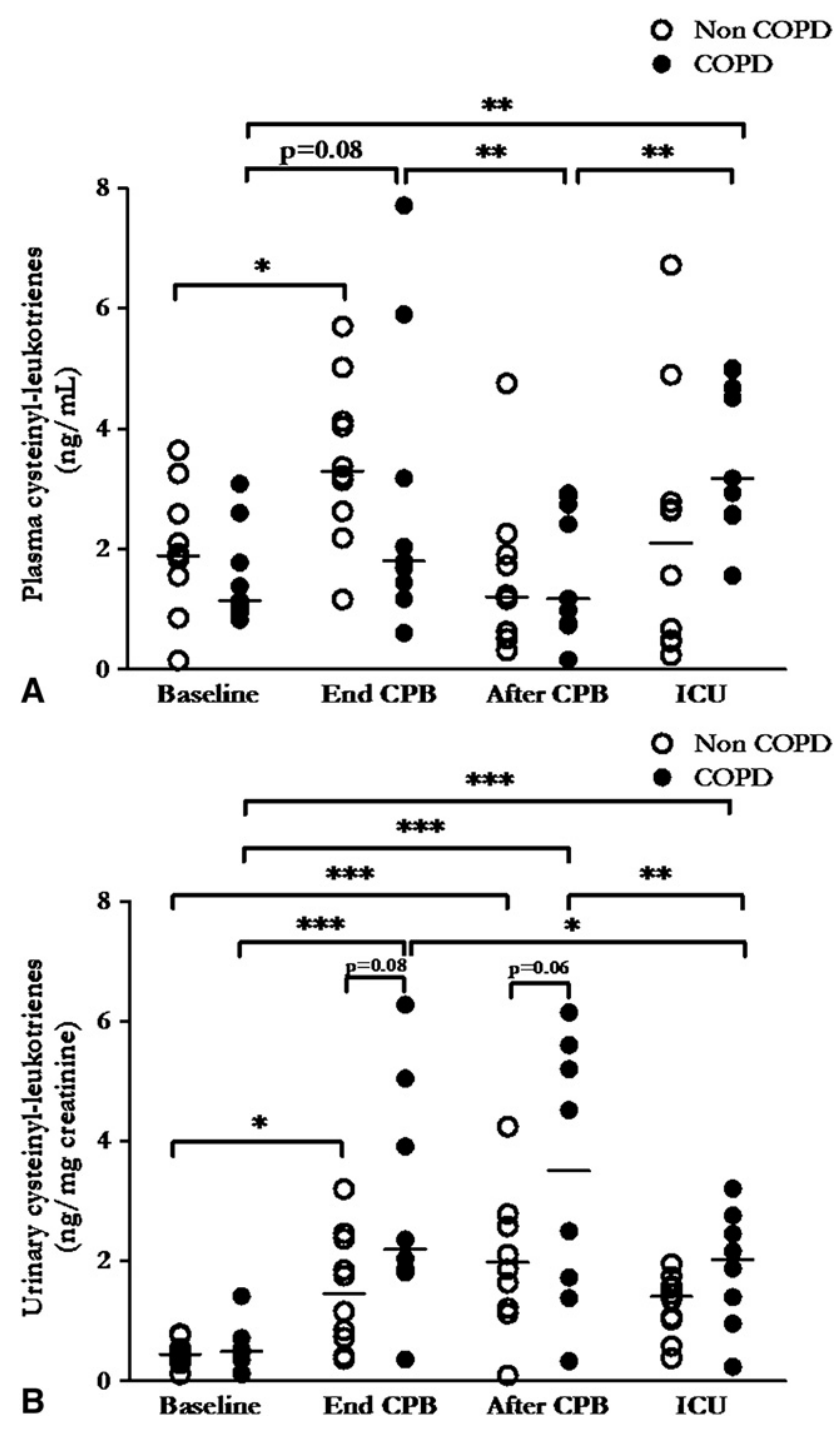

FIGURE 2. Plasma (A) and urinary (B) cysteinyl leukotriene concentrations in patients with chronic obstructive pulmonary disease (COPD, filled circles, $\mathrm{n}=9$ for plasma and $\mathrm{n}=8$ for urine samples) and without chronic obstructive pulmonary disease (non-COPD, open circles, $\mathrm{n}=10$ ) at 4 major interventional phases: before sternotomy (Baseline), at the end of cardiopulmonary bypass with continued extracorporeal circulation (End $C P B$ ), after cardiopulmonary bypass but before chest closure (After $C P B$ ), and 2 hours after intensive care unit admission (ICU). Horizontal bars represent median values. Single asterisk indicates $P<.05$; double asterisk indicates $P<.01$; triple asterisk indicates $P<.001$. $P$ values are derived from 2-way analysis of variance with repeated measurements, with Bonferroni adjustments for multiple comparisons.

plasma $\mathrm{LTB}_{4}$ concentrations were equivalent in patients who received aspirin $(\mathrm{n}=13,2.6 \pm 1.9 \mathrm{ng} / \mathrm{mL})$ and in those who did not $(\mathrm{n}=6,3.0 \pm 1.8 \mathrm{ng} / \mathrm{mL}, P=.65)$. Urinary $\mathrm{LTB}_{4}$ concentrations were not affected by time or group (Figure E3, B).

Tracheal aspirates. Tracheal aspirates were examined in only 8 patients with COPD. Concentrations of cysteinyl 
leukotrienes increased numerically but not statistically between baseline $(18.7 \pm 7.8 \mathrm{ng} / \mathrm{mL})$ and after CPB $(24.9 \pm$ $8.5 \mathrm{ng} / \mathrm{mL}, P=.35$; Figure $\mathrm{E} 4, A)$. $\mathrm{LTB}_{4}$ levels were similar at baseline $(8.9 \pm 2.3 \mathrm{ng} / \mathrm{mL})$ and after CPB $(9.7 \pm 2.2 \mathrm{ng} /$ $\mathrm{mL}, P=.19$; Figure $\mathrm{E} 4, B)$. Tracheal aspirate concentrations were approximately 9.1 times higher than plasma concentrations for cysteinyl leukotrienes and 3.3 times higher for $\mathrm{LTB}_{4}$.

\section{DISCUSSION}

The main results of this study are as follows: (1) Patients with COPD had higher airway resistances, poorer oxygenation on ICU admission, and longer duration of mechanical ventilation than did patients without COPD. (2) There was a significant increase in cysteinyl leukotriene production in the perioperative period of cardiac surgery with CPB. (3) This increase was greater in patients with COPD than in patients without $\mathrm{COPD}$, as quantified by urinary cysteinyl leukotrienes. (4) In contrast, $\mathrm{LTB}_{4}$ production did not increase significantly with time in blood or urine samples and did not differ between groups.

We observed poorer respiratory mechanics, lower oxygenation, and longer duration of mechanical ventilation in patients with COPD than in patients without COPD. These findings are consistent with previous reports of respiratory dysfunction during CABG and higher perioperative morbidity in patients with $\mathrm{COPD}^{5,22,23}$ and emphasize the clinical relevance of studying the mechanisms of postoperative respiratory failure in this subgroup of patients. Reasons for the worse lung function in patients with COPD, as observed in this study, are likely to be multifactorial, including atelectasis, hydrostatic pulmonary edema, and the systemic inflammatory response syndrome. These perioperative insults could exacerbate the chronic loss of elastic recoil and airway obstruction in COPD. ${ }^{4}$

Time courses of white blood cell and platelet counts were similar in the 2 groups, consistent with previous reports ${ }^{4,24}$ and suggesting that more severe pulmonary dysfunction in patients with COPD was likely due to group differences other than accumulation of those cells in the lungs. ${ }^{24}$

\section{Systemic Release of Cysteinyl Leukotrienes During CPB}

We measured plasma and urinary levels of cysteinyl leukotrienes to obtain a sequential picture of leukotriene production. Because of the short half-life of plasma cysteinyl leukotrienes (about 7 minutes in healthy human subjects), ${ }^{25}$ plasma levels are likely to reflect acute changes in systemic cysteinyl leukotriene production. On the other hand, urinary levels of cysteinyl leukotrienes characterize cumulative production of systemic cysteinyl leukotrienes during the preceding hours. $^{25-27}$

We found a significant increase in cysteinyl leukotriene production in the perioperative period of cardiac surgery with $\mathrm{CPB}$, starting early in the intraoperative period at the end of CPB. Comparison of our findings with the literature is limited, because data are scarce on intraoperative changes in cysteinyl leukotrienes during CPB and on simultaneous blood and urinary cysteinyl leukotriene measurements. Nonetheless, our results of higher urinary cysteinyl leukotrienes in the ICU than at baseline are consistent with the findings of Allen and colleagues, ${ }^{13}$ who showed an increased urinary production of leukotriene $\mathrm{E}_{4}$ in the days after CABG surgery.

The finding of increased plasma cysteinyl leukotrienes at the end of CPB relative to baseline suggests that the 5-lipoxygenase pathway is activated at or before this time point. Accordingly, urinary cysteinyl leukotriene levels, which represent cumulative cysteinyl leukotriene production, ${ }^{25-27}$ tended to be larger at the end of CPB than at baseline, suggesting that cysteinyl leukotriene production starts before the end of CPB. This consistency between our plasma and urinary measurements strengthens our finding that an acute increase in the perioperative production of cysteinyl leukotrienes occurs during cardiac surgery with CPB.

Several factors could lead to increased cysteinyl leukotriene production. First, activation of the alternative complement pathway through contact of blood with CPB circuits results in increased adhesion of human neutrophils to the endothelium, ${ }^{4}$ potentially resulting in increased production of cysteinyl leukotrienes by neutrophils. Neutrophils also have an ability to export leukotriene $\mathrm{A}_{4}$ (a common precursor of $\mathrm{LTB}_{4}$ and cysteinyl leukotrienes) to platelets and endothelial cells for conversion to leukotrienes. ${ }^{6}$ Finally, cell types present in the coronary artery plaque (mast cells and basophils, monocytes and macrophages, endothelial cells) produce cysteinyl leukotrienes. For example, acute systemic release of cysteinyl leukotrienes in coronary blood occurs minutes after percutaneous transluminal coronary angioplasty. ${ }^{21}$ Similarly, manipulation of diseased coronary arteries during CABG could have promoted the release of cysteinyl leukotrienes into the bloodstream. ${ }^{21}$ The decrease in plasma cysteinyl leukotriene concentrations after coronary reperfusion (after $\mathrm{CPB}$ ), the similar number of CABG cases in each group, and the equivalent pattern of leukotriene changes in CABG and non-CABG cases suggest that differential release of leukotrienes in CABG cases was not a major factor in our study.

After CPB, plasma cysteinyl leukotriene concentrations decreased to a nadir comparable to baseline values (Figure 2, $A$ ), whereas urinary cysteinyl leukotriene concentrations were higher than at baseline (Figure 2, B). Such observations reinforce the proposition that cysteinyl leukotriene production occurred predominantly during the $\mathrm{CPB}$ period.

Importantly, the increase in urinary cysteinyl leukotrienes was greater in patients with COPD than in patients 
without COPD. This, to the best of our knowledge, is a new finding in the setting of cardiac surgery with CPB. Various factors could contribute to this finding. Stimulated peripheral neutrophils of patients with COPD produce more leukotriene $\mathrm{C}_{4}$ than do those of healthy subjects. ${ }^{28}$ Cardiac surgery and CPB have been associated with activation of peripheral neutrophils in patients in vivo. ${ }^{29,30}$ Thus neutrophil activation may have led to our observation of enhanced cysteinyl leukotriene production in patients with COPD. In addition, cysteinyl leukotrienes can also be produced in the lungs, as previously shown in patients with adult distress syndrome. ${ }^{11}$ Greater lung production of cysteinyl leukotrienes in patients with COPD than in patients without COPD thus may have contributed to the higher urinary cysteinyl leukotriene levels observed in the COPD group.

Measurements of cysteinyl leukotrienes in tracheal aspirates in 8 patients with COPD demonstrated high concentrations, suggesting that cysteinyl leukotrienes were probably at least in part produced in lungs (Figure E4, A). Further studies comparing tracheal aspirate measurements of cysteinyl leukotrienes in patients with and without COPD are needed to draw further conclusion regarding the sites of production of cysteinyl leukotrienes during $\mathrm{CPB}$.

Finally, our finding of a trend in the association between plasma cysteinyl leukotriene levels on ICU admission and duration of mechanical ventilation, in conjunction with all other findings, allows us to speculate on a causal relationship between cysteinyl leukotriene production and pulmonary outcome. A specific interventional study will be required to establish such causality.

\section{Systemic Release of $\mathrm{LTB}_{\mathbf{4}}$ During CPB}

Plasma and urinary concentrations of $\mathrm{LTB}_{4}$ did not change significantly with time (Figure E3). Data on production of $\mathrm{LTB}_{4}$ during clinical and experimental CPB are conflicting, with findings of both increased ${ }^{12,17}$ and unchanged ${ }^{31}$ levels perioperatively. The discrepancy between our findings and reports of increased blood neutrophil $\mathrm{LTB}_{4}$ generation during $\mathrm{CPB}^{17}$ may be related to the use of distinct measurement methods. Gadaleta and coworkers ${ }^{17}$ used in vitro assays to quantify the potential production of $\mathrm{LTB}_{4}$ after incubating neutrophils with a calcium ionophore, ${ }^{6}$ instead of assessing existing $\mathrm{LTB}_{4}$ plasma levels as we did. In addition, recent progress in the biocompatibility of CPB circuits has reduced production of inflammatory mediators, ${ }^{32}$ potentially including $\mathrm{LTB}_{4}$.

\section{Limitations and Perspectives of Study}

This single-center study has several limitations. Our results do not allow us to draw any cause-effect relationship between cysteinyl leukotriene levels and pulmonary dysfunction. Perioperative respiratory dysfunction during cardiac surgery is multifactorial. Specific inhibition of the cysteinyl leukotriene pathway would therefore be the best method to assess its role in the pathophysiology of postoperative pulmonary dysfunction after $\mathrm{CPB}$ and in patients with COPD. Available oral cysteinyl leukotriene receptor antagonists significantly protect against bronchoconstriction as early as 2 hours after administration and for as long as 24 hours. ${ }^{9,33}$ A phase II randomized, controlled study assessing the effect of such an intervention on the incidence of postoperative pulmonary dysfunction thus appears both feasible and desirable.

Aspirin therapy has previously been shown to increase the production of 5-lipoxygenase metabolites (leukotrienes) in vivo through inhibition of cyclooxygenase. ${ }^{21}$ Because we did not measure cyclooxygenase metabolites, ${ }^{34}$ we are unable to quantify the magnitude of cyclooxygenase inhibition and any potential effect of aspirin on the production of leukotrienes during cardiac surgery with CPB. Because the same proportion of patients received aspirin in both groups (Table E1) and mean concentrations of cysteinyl leukotrienes and $\mathrm{LTB}_{4}$ were similar in patients who received aspirin and in those who did not, it is unlikely that an aspirin effect would explain our results.

Finally, this study included a small number of patients, and most of the patients with COPD $(n=8 / 9)$ were in Global Initiative for Chronic Obstructive Lung Disease stage $\mathrm{IIa}^{19}$ (force expiratory volume of at least $50 \%$ but less than $80 \%$ ). As such, shortcomings of a small, singlecenter study apply, such as limited characterization of the entire population of patients with and without COPD, potential bias of the studied population, and inability to directly extrapolate our results to other subgroups of patients with COPD.

\section{CONCLUSIONS}

In conclusion, our study shows that systemic release of cysteinyl leukotrienes increases with time during the perioperative period of cardiac surgery with CPB. This increase is already apparent at the end of the CPB time. Patterns of change in cysteinyl leukotrienes differ between patients with and without COPD, with patients with COPD showing higher urinary cysteinyl leukotriene levels in the perioperative period. This difference may be related to higher lung and airway production of cysteinyl leukotrienes and increased activation of neutrophils in patients with COPD. $\mathrm{LTB}_{4}$ production did not differ between patients with and without COPD and did not increase with time.

We thank Dr Charles N. Serhan (Brigham and Women's hospital, Harvard Medical School, Boston, Mass) for his precious support in analyzing and interpreting the data, Drs Eduardo L. Costa and Juan Jose Nieves for their contribution with enzymelinked immunosorbent assay measurements, Dr Ivany Schettino for collaboration in the study design, Dr Hui Zheng for reviewing the statistical analysis, and Barbara Hill Pellegrini, RN, Laura 
Collier, RN, Christine Angelini, RN, Rosemary Daggett, RN, Katy Zanetti, RN, Susan Aylouche, RN, Adrianne Diamond, RN, Cindy Cooney, RN, Trish Meyer, RN, Kerry Crisalli, RN, Beth McLaughlin, RN, Sharon Zisk, RN, and Jennifer Mills, RN, for their help with intraoperative blood samples.

\section{References}

1. Kung HC, Hoyert DL, Xu J, Murphy SL. Deaths: final data for 2005. Natl Vital Stat Rep. 2008;56:1-120.

2. Gardner SC, Grunwald GK, Rumsfeld JS, Mackenzie T, Gao D, Perlin JB, et al. Risk factors for intermediate-term survival after coronary artery bypass grafting. Ann Thorac Surg. 2001;72:2033-7.

3. Clough RA, Leavitt BJ, Morton JR, Plume SK, Hernandez F, Nugent W, et al. The effect of comorbid illness on mortality outcomes in cardiac surgery. Arch Surg. 2002;137:428-33.

4. Asimakopoulos G, Smith PL, Ratnatunga CP, Taylor KM. Lung injury and acute respiratory distress syndrome after cardiopulmonary bypass. Ann Thorac Surg. 1999;68:1107-15.

5. Samuels LE, Kaufman MS, Morris RJ, Promisloff R, Brockman SK. Coronary artery bypass grafting in patients with COPD. Chest. 1998;113:878-82.

6. Peters-Golden M, Henderson WR Jr. Leukotrienes. N Engl J Med. 2007;357: 1841-54.

7. Samuelsson B, Dahlén SE, Lindgren JA, Rouzer CA, Serhan CN. Leukotrienes and lipoxins: structures, biosynthesis, and biological effects. Science. 1987; 237:1171-6.

8. Horwitz RJ, McGill KA, Busse WW. The role of leukotriene modifiers in the treatment of asthma. Am J Respir Crit Care Med. 1998;157:1363-71.

9. Zühlke IE, Kanniess F, Richter K, Nielsen-Gode D, Böhme S, Jörres RA, et al Montelukast attenuates the airway response to hypertonic saline in moderateto-severe COPD. Eur Respir J. 2003;22:926-30.

10. Caironi P, Ichinose F, Liu R, Jones RC, Bloch KD, Zapol WM. 5-Lipoxygenase deficiency prevents respiratory failure during ventilator-induced lung injury. $\mathrm{Am}$ J Respir Crit Care Med. 2005;172:334-43.

11. Matthay MA, Eschenbacher WL, Goetzl EJ. Elevated concentrations of leukotriene D4 in pulmonary edema fluid of patients with the adult respiratory distress syndrome. J Clin Immunol. 1984;4:479-83.

12. Denizot Y, Feiss P, Nathan N. Are lipid mediators implicated in the production of pro- and anti-inflammatory cytokines during cardiopulmonary bypass graft with extracorporeal circulation? Cytokine. 1999;11:301-4.

13. Allen SP, Sampson AP, Piper PJ, Chester AH, Ohri SK, Yacoub MH. Enhanced excretion of urinary leukotriene E4 in coronary artery disease and after coronary artery bypass surgery. Coron Artery Dis. 1993;4:899-904.

14. Christenson JT, Aeberhard JM, Badel P, Pepcak F, Maurice J, Simonet F, et al. Adult respiratory distress syndrome after cardiac surgery. Cardiovasc Surg. 1996;4:15-21.

15. Corhay JL, Henket M, Nguyen D, Duysinx B, Sele J, Louis R. Leukotriene B4 contributes to exhaled breath condensate and sputum neutrophil chemotaxis in COPD. Chest. 2009;136:1047-54.

16. Moloney ED, Mumby SE, Gajdocsi R, Cranshaw JH, Kharitonov SA, Quinlan GJ, et al. Exhaled breath condensate detects markers of pulmonary inflammation after cardiothoracic surgery. Am J Respir Crit Care Med. 2004; 169:64-9.

17. Gadaleta D, Fahey AL, Verma M, Ko W, Kreiger KH, Isom OW, et al. Neutrophil leukotriene generation increases after cardiopulmonary bypass. J Thorac Cardiovasc Surg. 1994;108:642-7.
18. Utoh J, Yamamoto T, Miyauchi Y. Is an increase in neutrophil leukotrienegenerating capacity a specific phenomenon for cardiopulmonary bypass? $J$ Thorac Cardiovasc Surg. 1995;110:276-7.

19. Rabe KF, Hurd S, Anzueto A, Barnes PJ, Buist SA, Calverley P, et al. Global strategy for the diagnosis, management, and prevention of chronic obstructive pulmonary disease: GOLD executive summary. Am J Respir Crit Care Med. 2007; 176:532-55.

20. Moreno RP, Metnitz PG, Almeida E, Jordan B, Bauer P, Campos RA, et al. SAPS 3 -From evaluation of the patient to evaluation of the intensive care unit. Part 2: Development of a prognostic model for hospital mortality at ICU admission. Intensive Care Med. 2005;31:1345-55. Erratum in: Intensive Care Med. 2006;32: 796.

21. Brezinski DA, Nesto RW, Serhan CN. Angioplasty triggers intracoronary leukotrienes and lipoxin A4. Impact of aspirin therapy. Circulation. 1992;86: 56-63.

22. Staton GW, Williams WH, Mahoney EM, Hu J, Chu H, Duke PG, et al. Pulmonary outcomes of off-pump vs on-pump coronary artery bypass surgery in a randomized trial. Chest. 2005; 127:892-901.

23. Cohen A, Katz M, Katz R, Hauptman E, Schachner A. Chronic obstructive pulmonary disease in patients undergoing coronary artery bypass grafting. J Thorac Cardiovasc Surg. 1995;109:574-81.

24. Brix-Christensen V, Tønnesen E, Hjortdal VE, Chew M, Flø C, Marqversen J, et al. Neutrophils and platelets accumulate in the heart, lungs, and kidneys after cardiopulmonary bypass in neonatal pigs. Crit Care Med. 2002;30:670-6.

25. Sala A, Voelkel N, Maclouf J, Murphy RC. Leukotriene E4 elimination and metabolism in normal human subjects. J Biol Chem. 1990;265:21771-8.

26. Maclouf J, Antoine C, De Caterina R, Sicari R, Murphy RC, Patrignani P, et al. Entry rate and metabolism of leukotriene $\mathrm{C} 4$ into vascular compartment in healthy subjects. Am J Physiol. 1992;263(1 Pt 2):H244-9.

27. Denzlinger C, Guhlmann A, Scheuber PH, Wilker D, Hammer DK, Keppler D. Metabolism and analysis of cysteinyl leukotrienes in the monkey. J Biol Chem. 1986;261:15601-6.

28. Mitsunobu F, Mifune T, Hosaki Y, Ashida K, Tsugeno H, Okamoto M, et al. Enhanced production of leukotrienes by peripheral leukocytes and specific IgE antibodies in patients with chronic obstructive pulmonary disease. J Allergy Clin Immunol. 2001;107:492-8.

29. Evans BJ, Haskard DO, Finch JR, Hambleton IR, Landis RC, Taylor KM. The inflammatory effect of cardiopulmonary bypass on leukocyte extravasation in vivo. J Thorac Cardiovasc Surg. 2008;135:999-1006.

30. Ilton MK, Langton PE, Taylor ML, Misso NL, Newman M, Thompson PJ, et al. Differential expression of neutrophil adhesion molecules during coronary artery surgery with cardiopulmonary bypass. J Thorac Cardiovasc Surg. 1999;118: 930-7.

31. Friedman M, Sellke FW, Wang SY, Weintraub RM, Johnson RG. Parameters of pulmonary injury after total or partial cardiopulmonary bypass. Circulation. 1994;90(5 Pt 2):II262-8.

32. de Vroege R, van Oeveren W, van Klarenbosch J, Stooker W, Huybregts MA, Hack CE, et al. The impact of heparin-coated cardiopulmonary bypass circuits on pulmonary function and the release of inflammatory mediators. Anesth Analg. 2004;98:1586-94. table of contents

33. Pearlman DS, van Adelsberg J, Philip G, Tilles SA, Busse W, Hendeles L, et al. Onset and duration of protection against exercise-induced bronchoconstriction by a single oral dose of montelukast. Ann Allergy Asthma Immunol. 2006;97: 98-104.

34. Patrono C, Ciabattoni G, Pinca E, Pugliese F, Castrucci G, De Salvo A, et al. Low dose aspirin and inhibition of thromboxane B2 production in healthy subjects. Thromb Res. 1980;17:317-27. 
COPD

- Non-COPD
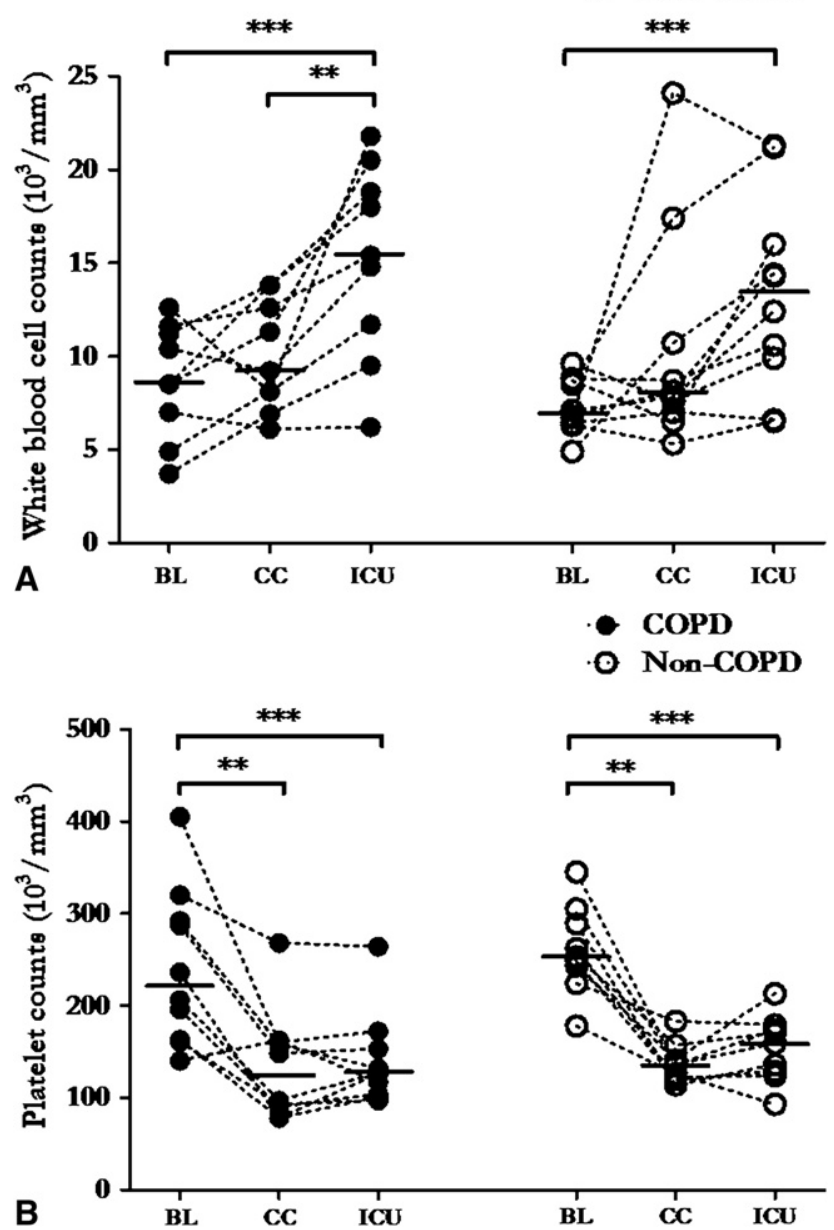

FIGURE E1. White blood cell (A) and platelet (B) counts in patients with chronic obstructive pulmonary disease $(C O P D$, filled circles, $\mathrm{n}=9)$ and without chronic obstructive pulmonary disease (non-COPD, open circles, $\mathrm{n}=10)$ at baseline before sternotomy $(B L)$, after chest closure $(C C)$, and 2 hours after intensive care unit admission $(I C U)$. Horizontal bars represent median values. Double asterisk indicates $P<.01$; triple asterisk indicates $P<.001$.

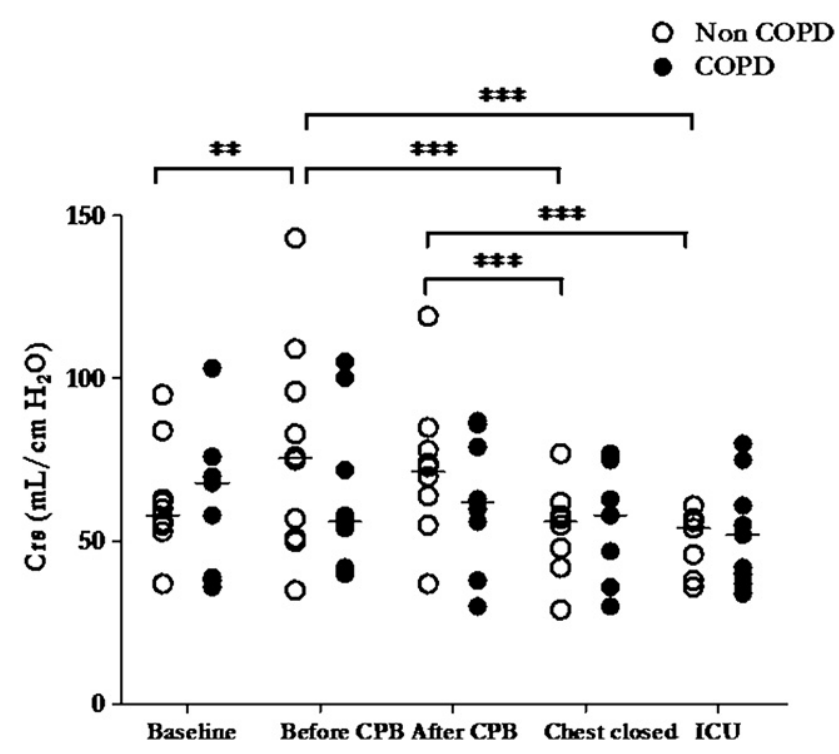

FIGURE E2. Compliance of the respiratory system $(\mathrm{Crs})$ in patients with chronic obstructive pulmonary disease (COPD, filled circles, $\mathrm{n}=9)$ and without chronic obstructive pulmonary disease (non-COPD, open circles, $\mathrm{n}=10)$ at 5 major interventional phases: before sternotomy (Baseline), before and after cardiopulmonary bypass $(C P B)$, after chest closure (chest closed), and 2 hours after intensive care unit admission (ICU). Horizontal bars represent median values. Double asterisk indicates $P<.01$; triple asterisk indicates $P<.001$. $P$ values are derived from 2-way analysis of variance with repeated measurements, with Bonferroni adjustments for multiple comparisons. 

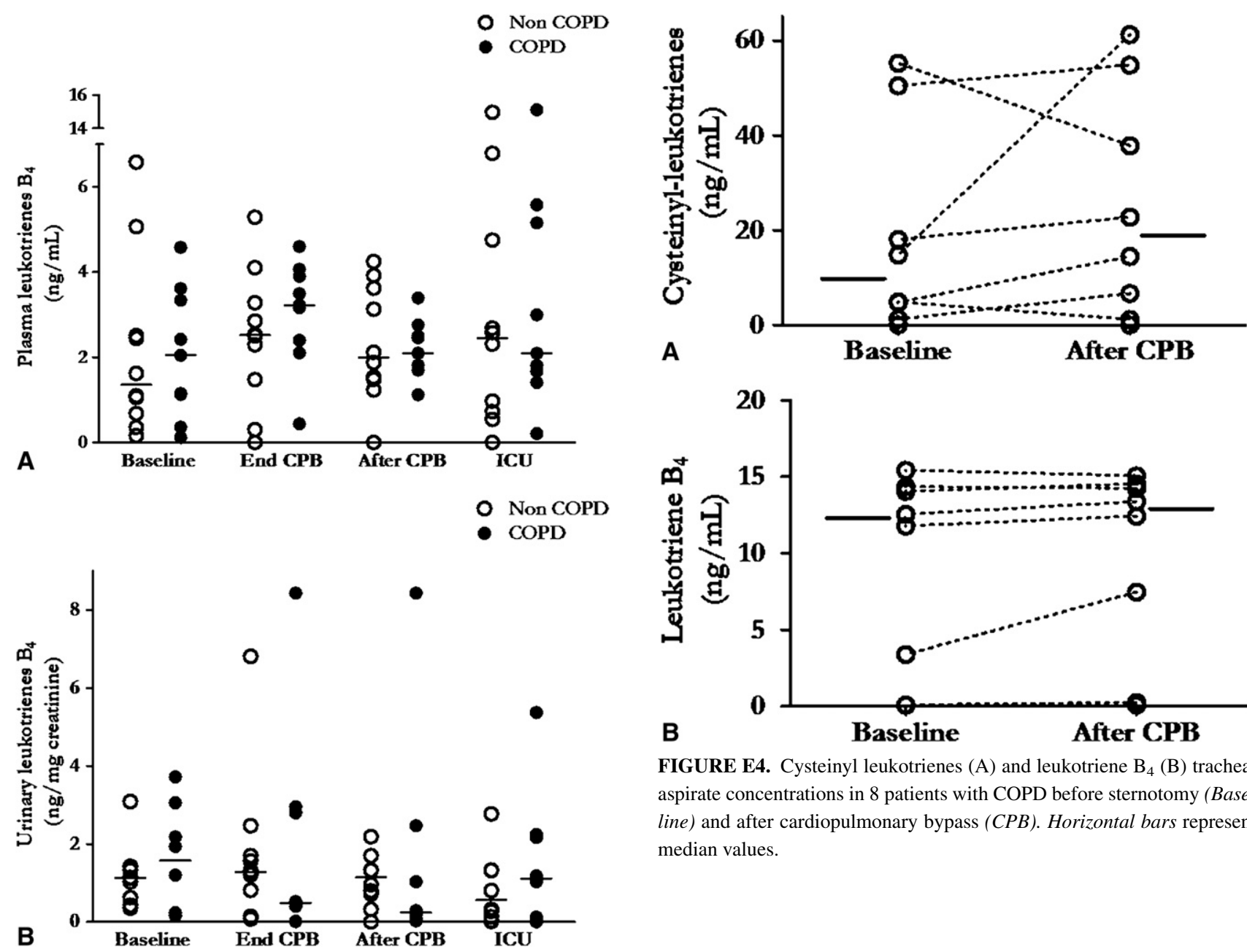

FIGURE E3. Plasma (A) and urinary (B) leukotriene $\mathrm{B}_{4}$ concentrations of patients with chronic obstructive pulmonary disease (COPD, filled circles, $\mathrm{n}=9$ for plasma and $\mathrm{n}=8$ for urine samples) and without chronic obstructive pulmonary disease (non-COPD, open circles, $\mathrm{n}=10$ ) at 4 major interventional phases: before sternotomy (Baseline), at the end of cardiopulmonary bypass with continued extracorporeal circulation (End $C P B$ ), after cardiopulmonary bypass but before chest closure (After $C P B$ ), and 2 hours after intensive care unit admission (ICU). Horizontal bars represent

median values.

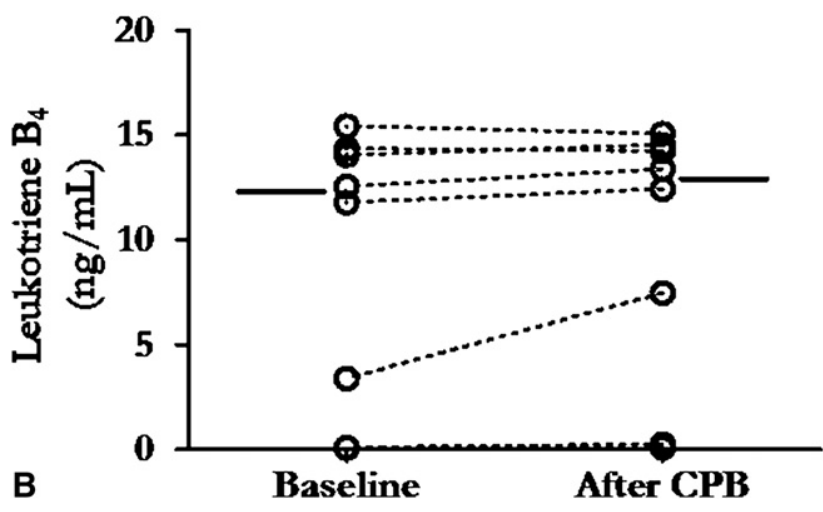

FIGURE E4. Cysteinyl leukotrienes (A) and leukotriene $\mathrm{B}_{4}$ (B) tracheal aspirate concentrations in 8 patients with COPD before sternotomy (Baseline) and after cardiopulmonary bypass $(C P B)$. Horizontal bars represent median values. 
TABLE E1. Patient characteristics

\begin{tabular}{|c|c|c|c|c|c|c|c|c|c|c|}
\hline Case & Sex & Age (y) & COPD & GOLD & $\begin{array}{l}\text { Smoking } \\
\text { (pack-y) }\end{array}$ & $\begin{array}{c}\text { BMI } \\
\left(\mathrm{kg} / \mathrm{cm}^{2}\right)\end{array}$ & Aspirin & $\begin{array}{l}\text { Inhaled } \\
\text { steroids }\end{array}$ & $\begin{array}{l}\text { Preoperative chest } \\
\text { radiograph } \\
\end{array}$ & $\begin{array}{l}\text { Type of } \\
\text { surgery }\end{array}$ \\
\hline 1 & M & 81 & No & NA & 0 & 27.1 & Yes & No & Normal & AVR, $\mathrm{CABG} \times 1$ \\
\hline 2 & M & 63 & No & NA & 0 & 30.5 & Yes & No & Normal & $\mathrm{CABG} \times 2$ \\
\hline 3 & $\mathrm{~F}$ & 71 & No & NA & 0 & 28.1 & No & No & Normal & AVR \\
\hline 4 & M & 50 & No & NA & 0 & 19.8 & No & No & Normal & ARR \\
\hline 5 & M & 73 & No & NA & 0 & 26.5 & Yes & No & Normal & $\mathrm{CABG} \times 3$ \\
\hline 6 & M & 76 & No & NA & 0 & 23.0 & Yes & No & Normal & $\mathrm{CABG} \times 3$ \\
\hline $7 *$ & M & 53 & No & NA & 0 & 22.6 & No & No & Normal & MVR \\
\hline 8 & M & 61 & No & NA & 0 & 23.6 & Yes & No & Normal & $\mathrm{CABG} \times 3$ \\
\hline 9 & $\mathrm{~F}$ & 53 & No & NA & 0 & 24.5 & Yes & No & Normal & $\mathrm{CABG} \times 3$ \\
\hline 10 & $\mathrm{~F}$ & 57 & No & NA & 0 & 22.0 & Yes & No & Normal & LVMR \\
\hline 11 & $\mathrm{~F}$ & 66 & Yes & IIa & 150 & 34.1 & Yes & No & Normal & $\mathrm{CABG} \times 2$ \\
\hline 12 & M & 82 & Yes & $\mathrm{IIb}$ & 65 & 21.8 & No & Yes & $\mathrm{P} / \mathrm{E}$ & AVR \\
\hline 13 & M & 76 & Yes & IIa & 60 & 25.8 & Yes & No & Distention & $\mathrm{CABG} \times 2$ \\
\hline 14 & M & 61 & Yes & IIa & 90 & 18.5 & No & No & Normal & $\mathrm{CABG} \times 3$ \\
\hline 15 & M & 57 & Yes & IIa & 80 & 26.9 & Yes & No & Normal & $\mathrm{CABG} \times 5$ \\
\hline 16 & $\mathrm{~F}$ & 75 & Yes & IIa & 100 & 43.3 & Yes & Yes & Normal & $\mathrm{CABG} \times 2$ \\
\hline 17 & M & 63 & Yes & IIa & 120 & 37.3 & No & No & $\mathrm{P} / \mathrm{E}, \mathrm{CPE}$ & $\mathrm{CABG} \times 4$ \\
\hline 18 & $\mathrm{~F}$ & 80 & Yes & IIa & 50 & 30.3 & Yes & Yes & $\mathrm{P} / \mathrm{E}, \mathrm{CPE}$ & AVR, CABG $\times$ \\
\hline 19 & M & 65 & Yes & IIa & 150 & 18.0 & Yes & Yes & Distention & MVR \\
\hline
\end{tabular}

$C O P D$, Chronic obstructive pulmonary disease; $G O L D$, Global Initiative for Chronic Obstructive Lung Disease classification ${ }^{19} ; B M I$, body mass index; $M$, male; $N A$, not applicable; $A V R$, aortic valve repair; $C A B G$, coronary artery bypass grafting; $F$, female; $A R R$, aortic root replacement; $M V R$, mitral valve repair; $L V$, left ventricular mass resection; $P / E$, pleural effusion; $C P E$, cardiogenic pulmonary edema. *Venous access for cardiopulmonary bypass was performed with direct cannulation of both superior and inferior venae cavae.

TABLE E2. Hospital course of patients with and without chronic obstructive pulmonary disease

\begin{tabular}{|c|c|c|c|}
\hline & COPD $(\mathbf{n}=9)$ & No COPD $(\mathbf{n}=10)$ & $P$ value \\
\hline Duration of mechanical ventilation $(h$, mean $\pm S D)$ & $13.7 \pm 5.8$ & $6.8 \pm 3.4$ & $<.01$ \\
\hline $\begin{array}{l}\text { Duration of intensive care unit stay } \\
\qquad(\mathrm{d}, \text { median and interquartile range })^{*}\end{array}$ & $2(1-3)$ & $1(1-3)$ & .27 \\
\hline Postoperative atrial fibrillation (no.) & $7(78 \%)$ & $3(30 \%)$ & .24 \\
\hline Postoperative pneumonia (no.) & $1(11 \%)$ & $0(0 \%)$ & $>.999$ \\
\hline In-hospital mortality (no.) & $1(11 \%)$ & $0(0 \%)$ & $>.999$ \\
\hline
\end{tabular}

COPD, Chronic obstructive pulmonary disease. ${ }^{*} P$ value according to Mann-Whitney test. 